\title{
Recent advancements in mechanical characterisation of 3D woven composites
}

\author{
Mohamed Nasr Saleh $^{1 *}$ and Constantinos Soutis ${ }^{2}$
}

\begin{abstract}
Three dimensional (3D) woven composites have attracted the interest of academia and industry thanks to their damage tolerance characteristics and automated fabric manufacturing. Although much research has been conducted to investigate their out-of-plane "through thickness" properties, still their in-plane properties are not fully understood and rely on extensive experimentation. To date, the literature lacks an inclusive summary of the mechanical characterisation for 3D woven composites. Therefore, the objective of this paper is to provide a comprehensive review of the available research studies on 3D woven composites mechanical characterisation, with less emphasis on the outof-plane response, but an in-depth review of the in-plane response "un-notched vs. notched". The paper highlights the knowledge gap in the literature of 3D woven composites, suggesting opportunities for future research in this field and a room for improvement in utilising Non-Destructive Techniques (NDT), such as Digital Image Correlation (DIC), Acoustic Emission (AE) and X-ray Computed Tomography (CT), for observing damage initiation and evolution in 3D woven composites that could be used to calibrate and evaluate analytical and numerical models.
\end{abstract}

Keywords: 3D textile composites, Mechanical properties, Damage mechanics

\section{Introduction}

Two-dimensional (2D) laminated composites are characterised by their in-plane high specific stiffness and strength (Ansar et al. 2011). However, many real life applications are exposed to out-of-plane loading conditions that make it impossible to resort to the 2D laminates as the proper solution. Wind turbine blades, stringers and stiffeners in aircraft, pressure vessels and construction applications are some examples of applications in which outof-plane loading conditions are imposed on the structure. Thus, the need for composite materials with enhanced through-thickness "out-of-plane" properties has emerged. This need requires replacing 2D laminated composites with three-dimensional (3D) textile structures in which binding/stitching yarns are introduced in the z-direction. The "enhanced out-of-plane properties" is not the only advantage of 3D composites. The delamination resistance, due to the use of z-binders, enhances the impact performance and damage tolerance of such material systems (Mcclain et al. 2012). In addition, using textile technology

\footnotetext{
* Correspondence: mohamed.saleh@sheffield.ac.uk

${ }^{1}$ Advanced Manufacturing Research Centre with Boeing, University of

Sheffield, S60 5TZ, Rotherham, UK

Full list of author information is available at the end of the article
}

can be utilised to manufacture near-net-shape preforms which reduces the manufacturing/machining cost and time even further. Although various techniques exist for manufacturing 3D textile preforms such as stitching, braiding, weaving and knitting, the most widely used nowadays is weaving due to its high production rate along with the ability to produce various 3D woven structures (Ansar et al. 2011).

Generally, 3D woven composites can be divided into two main groups depending on how deep the binder penetrates through the fabric. If it penetrates all the way through the thickness it is referred to as through-thickness (TT) interlock (see Fig. 1a, c) while it is classified as layer-to-layer (LTL) if the binder only holds adjacent layers (see Fig. 1b). Then this classification is further divided according to the interlacing angle of the structure. The first category is the angle interlock (AI) in which the interlacing angle between the binder and weft yarns can have any value except $90^{\circ}$ (Fig. 1c). The second category is a special case of the first one. The orthogonal interlock (ORT) (Fig. 1a) occurs when the interlacing angle between the binder and weft yarns is equal to $90^{\circ}$ (Ansar et al. 2011).

The weave pattern used during the weaving process can also affect the classification of 3D woven composites. For 

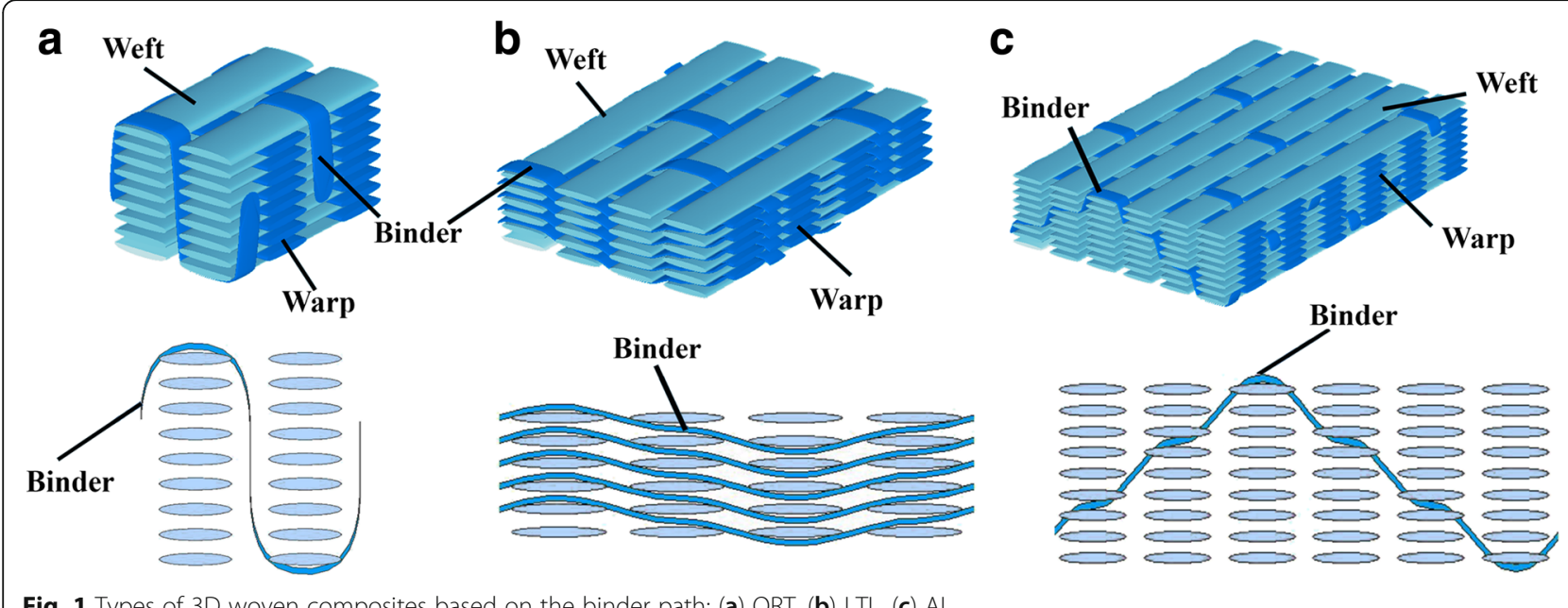

Fig. 1 Types of 3D woven composites based on the binder path: (a) ORT, (b) LTL, (c) Al

instance in the case of ORT weave, the frequency of the zbinder sweeping the top and bottom surfaces of the weave can vary from plain (Fig. 2a) to twill (Fig. 2b) or satin (Fig. 2c) pattern. This will directly affect the unit-cell size, degree of crimp, elastic response and damage/delamination resistance as it will be highlighted later in this paper.

From an industrial point of view, 3D woven LTL and AI architectures have been used in applications where load is required to be transferred around a bend such as brackets, curved beams and T-shaped profiles (Redman et al. 2014). In such applications, the developed architectures were reported to demonstrate more resistance to the interlaminar shear and radial stresses developed in service. In Automotive industries, LTL woven composite was used to replace the high-strength steel (HSST) beams (Bayraktar et al. 2015). In addition, McClain et al. (Mcclain et al. 2012) reported successful usage of LTL and AI architectures in truss beams with integral off-axis stiffeners as well as stiffened panels in which continuous fibres run from the skin into each stiffening element. In this way, the need for fasteners and bonds at joints is overcome which is one of the major challenges facing 2D laminated composites nowadays. ORT architecture has been successfully used in the LEAP project to manufacture fan blades and engine casings for A320neo, Comac C919 and 737-MAX as well as fuselage barrel stringers on long-range aircraft (Jewell et al. 2011). Another interesting application of ORT carbon fibre architectures was reported by Hemrick et al. (Hemrick et al. 2011) in ultra-light weight heat exchangers for vehicle radiators. The application made use of the high thermal conductivity of ORT architecture as the through-thickness binder creates a conduction path for the heat dissipation, In addition, Sharp et al. (Sharp et al. 2013) and Mohamed et al. (Mohamed and Wetzel 2006) have reported the usage of ORT architecture in wind turbine rotor blade applications. The concept was to integrate $\Pi$-joints with I-beam joints to connect the shear web and the spar cap in order to resist delamination and improve the damage tolerance of the blade.

In spite of the previously mentioned advantages of 3D composite preforms, still their applications are limited (Tong et al., 2009a; Warren et al. 2015a). One of the main reasons is the level of knowledge required to control the manufacturing process parameters. During the resin infusion process, it is essential and challenging, at the same time, to make sure that the resin has the ability to reach all the intricate locations in the 3D complex woven architecture in order not to have voids in the manufactured part. On the other hand, there may be regions of resin rich pockets in the manufactured composite. Many parameters affect the quality of the produced component such as the resin viscosity, the 3D woven composite architecture and the mould design. This requires a properly designed and controlled environment during the
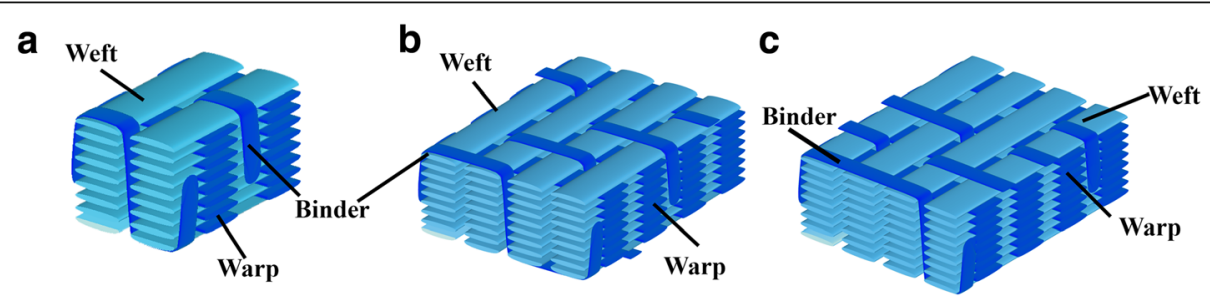

Fig. 2 Examples of possible weave patterns for ORT: (a) Plain, (b) Twill, (c) Satin 
infusion process. Additional manufacturing defects can be in the form of fibre breakage, in-plane fibre distortion or $\mathrm{z}$ binder fibre distortion. Tong reports a comprehensive study about the manufacturing defects and their possible causes (Tong et al., 2009b). In addition to the manufacturing challenges, 3D woven composites are characterised by lower in-plane properties compared to those of 2D laminated composites. This is due to the fibres' undulation or "crimp" caused by the interlacement of the longitudinal "warp" fibres, transverse "weft" fibres and z-binding fibres "binder" (Stig 2012). The influence of the crimp on the in-plane properties was studied by Stig (Stig and Hallström 2013). So, it is always a trade-off between the enhanced out-of-plane properties and the reduced in plane properties. This is an open area for optimising 3D woven composites according to specific applications. One last concern regarding 3D woven composites is to understand their mechanical behaviour in the elastic region; but more importantly when damage occurs. Although quite a reasonable amount of research has been done in this field, still more experimental work has to be carried out before expanding in the usage of 3D woven composites in engineering applications.

To date, the literature lacks a comprehensive summary of the mechanical characterisation work done for 3D woven composites. Therefore, the objective of this paper is to provide as much detailed and comprehensive review of the available research studies on 3D woven composites mechanical characterisation, with less emphasis on the out-ofplane response, but an in-depth review of the in-plane response "un-notched vs. notched". This paper is designed purely to address the advancement in experimental characterisation of $3 \mathrm{D}$ woven composites, but not the modelling aspect as it has been previously reviewed by Ansar et al. (Ansar et al. 2011). Section 2 will briefly discuss some of the previous studies of out-of-plane characterisation of 3D woven composites including impact/indentation, flexural and interlaminar shear strength (ILSS) testing. A comprehensive review of the un-notched in-plane response is then detailed in section 3 for both on-axis and off-axis orientations. Then, section 4 is dedicated to the notched response of 3D woven composites again for, on-axis and off-axis, open-hole tension and bearing strength testing. Finally, section 5 highlights the concluding remarks of this review and summarises in a tabulated format the different studies available in the literature for the different weaving architecture "ORT, LTL and AI".

\section{Out-of-plane properties characterisation Impact/indentation testing}

As the main advantage of 3D woven composites is clearly their out-of-plane enhanced properties, many researchers for example (Ji et al. 2007; Luo et al. 2007; Hao et al. 2008; Walter et al. 2009; Gerlach et al. 2012; Seltzer et al. 2013; Umer et al. 2016) studied the effect of the z-binding yarns on the impact damage behaviour and the energy absorption of those material systems. Impact testing in literature was classified based on the impact velocity to low (< $10 \mathrm{~m} / \mathrm{s}$ ) as reported in (Umer et al. 2016), high ( 20 to $50 \mathrm{~m} / \mathrm{s}$ ) as in (Ji et al. 2007; Hao et al. 2008) and ballistic $(\sim 900 \mathrm{~m} / \mathrm{s})$ as discussed in (Walter et al. 2009). Hao et al. (Hao et al. 2008) studied the behaviour of ORT woven glass fibre composite plate and T-beams subjected to quasi-static indentation and impact loadings. Global response in the form of load displacement and energy absorption curves was evaluated, and Finite Element Modelling (FEM) results were validated against them. The implemented model correlated well with their experimental findings. In addition, damage mechanisms in the case of the T-beam and the plate were compared. They reported higher energy absorption by the T-beam as opposed to the composite plate, for the same loading level. Another study by Ji et al. (Ji et al. 2007) investigated the quasi-static indentation and impact behaviour of a circular plate made of ORT woven glass fibre composite. The quasi-static indentation test was carried out using a MTS machine while the impact test was done using a modified split Hopkinson pressure bar apparatus. The damaged surfaces of the specimens were characterised afterwards and energy absorption was calculated to verify FEM models they produced. Luo et al. (Luo et al. 2007) carried out quasi-static indentation and transverse impact tests for ORT hybrid woven composites with aramid and glass fibre yarns. The focus of this study was the strain rate sensitivity effect on energy absorption. It was reported that the higher the impact velocity $(20,40,55 \mathrm{~m} / \mathrm{s})$, the higher the energy absorbed $(\sim 8,12,18 \mathrm{~J})$ by the composite. Regarding the damage/failure mechanisms, the quasi-static loaded specimens suffered from tensile failure on the bottom side and compressive failure on the top side. In the case of impact damage, three damage mechanisms were captured: matrix cracking, fibre breakage and fibres pullout. In contrast to the response of the laminated composites, the effect of the through-thickness binder was significant as it supressed the delamination. An interesting study by Seltzer et al. (Seltzer et al. 2013) revealed the damage mechanisms of 3D S2-glass, carbon and hybrid woven composites by X-ray Computed Tomography (CT) due to low-velocity impact. In addition, they compared the energy absorption of the 3D woven composites with that of 2D laminated counterparts. They reported that the energy absorbed by the 3D woven composites was approximately twice the energy absorbed by the 2D laminated composite. The X-ray images demonstrated that this higher energy absorption was due to the binding yarns delaying the delamination and providing integrity to the structure. The existence of binding yarns resulted in dissipating the energy by other damage mechanisms such as tow splitting, out-of-plane shear and extensive fibre breakage. 


\section{Flexural \& interlaminar shear strength testing}

The effect of z-binding yarns on the flexural and interlaminar shear strength of 3D woven composites has been studied by (Chou et al. 1992; Cox et al. 1994; Wang 2006; Tong et al., 2009b; Walter et al. 2010; Nasution et al. 2014; Behera and Dash 2015; Dai et al. 2015a; Umer et al. 2016; Labanieh et al. 2017). For ORT and 3D braided architecture, Wang et al. (Wang 2006) reported both the flexural "3-point bending" and ILSS responses. Failure modes for flexural testing were a combination of tensile and compressive failure modes with the tensile modes being more significant. Authors mentioned clearly that the short-beam test could not be considered as a valid measure of the ILSS of 3D woven composites as they would not fail in shear. The calculated shear at failure was referred to as "apparent interlaminar shear strength" which represented a lower bound for the interlaminar shear strength as specimens failed due to bending instead. However, authors claimed that failure due to interlaminar shear might have occurred prior to the bending failure.

Following this study, Tong et al. (Tong et al., 2009b) reported that flexure properties "modulus/strength" of 3D woven composites were found to be inferior to 2D laminates. With regards to the interlaminar shear short beam test, they reported, in a single graph, the normalised interlaminar shear strength versus the $\mathrm{z}$-binder volume fraction reported in previous studies. In some cases, a slight improvement in the ILSS properties was observed although in most cases no significant change was reported. On the contrary, Walter et al. (Walter et al. 2010) concluded in his study that 3D woven composites "ORT \& AI" tested in the short-beam configuration exhibited lower interlaminar shear strength when compared to 2D plain woven laminated composite as a baseline. It is useful for the discussion to highlight here that the first drop in the load is normally used to calculate the ILSS which may be misleading in the case od 3D woven composites. As the z-binding yarns cause higher crimp and stress concentrations, this accelerates the first damage to occur corresponding to the first load drop. However, the same z-binding yarns help resisting delamination and crack propagation leading to higher strain to failure of 3D woven composites compared to their 2D counterparts. This was supported by optical microscopy in this study revealing that delamination cracks were arrested by the z-binding yarns in the case of ORT leading to a homogenously distributed damage and different non-linear response compared to the baseline $2 \mathrm{D}$ architecture. This demonstrated the damage tolerance capabilities of 3D woven composites.

For better understanding of the damage evolution in quasi-static flexural testing, Umer et al. (Umer et al. 2016) utilised X-ray CT scans of the failed specimens after testing. Three different architectures "ORT, LTL, AI" were tested along the warp and weft directions. A significant difference between the weft and warp modulus $(\sim 1.7)$ and strength $(\sim 1.4)$ was attributed to the higher fibre volume fraction in the weft compared to the warp for LTL architecture. This effect was less in the case of ORT ( 1.14) and AI ( 1.1) in which the difference between the fibre volume fraction in the weft and warp was not significant. X-ray CT scans revealed that damage initiated at resin-rich areas and around the z-binding yarns. Authors reported that cracks propagation followed the z-binder yarns leading to final failure. Labanieh et al. (Labanieh et al. 2017) has recently investigated the effect of adding biased layers $\left(+\theta^{\circ} /-\theta^{\circ}\right)$ to classical ORT architecture on the interlaminar shear response using short-beam testing configuration. The two multiaxial ORT architectures were different from the stacking sequence point of view. One of them (referred to as IMA) had the biased layers $\left(+\theta^{\circ} /-\theta^{\circ}\right)$ adjacent to each other while they were separated by a $0^{\circ}$ layer in the second architecture (referred to as MA). Digital Image Correlation (DIC) was used to obtain full strain field across the thickness of the specimens during testing. Locations of macroscopic cracks initiation were captured and analysed successfully. For all the tested architectures, the z-binding yarns reduced the delamination growth. In addition, authors concluded that insertion of the biased layers, especially in the case of the MA architecture, improved the delamination resistance compared to a classical ORT architecture. This was justified by the reduction of the relative angle between successive yarn layers.

\section{Un-notched in-plane properties characterisation}

In this section, the un-notched in-plane characterisation of $3 \mathrm{D}$ woven composites is reviewed in detail. As a convention for all the studies to be discussed, the "on-axis" terminology represents the cutting orientation along the warp or the weft directions while the "off-axis" terminology refers to a $45^{\circ}$ cutting orientation as depicted in Fig. 3.

\section{On-axis}

For the in-plane properties' characterisation, much work has been done to characterise the failure mechanisms of 3D woven composites subjected to quasi-static loading (Cox et al. 1994, 1996; Pochiraju 1999; Leong et al. 2000; Tan et al. 2000; Quinn et al. 2008; Lomov et al. 2011; Gerlach et al. 2012; Visrolia and Meo 2013; Behera and Dash 2015; Warren et al. 2015a; Dai et al. 2015a) along the warp- or weftdirections. An early study by Cox et al. (Cox et al. 1994, 1996) studied the failure mechanisms of $3 \mathrm{D}$ woven composites (ORT, LTL) monotonically loaded in tension, compression and bending. They found that the dominant failure modes in 3D interlock woven composites were tow rupture and pull-out (tension case), delamination and kinkband formation (compression case), and a combination of those failure modes (bending case). Afterwards, Pochiraju and Chou (Pochiraju 1999) reported the behaviour of 3D woven composites (LTL, AI, Braided) under tension along 


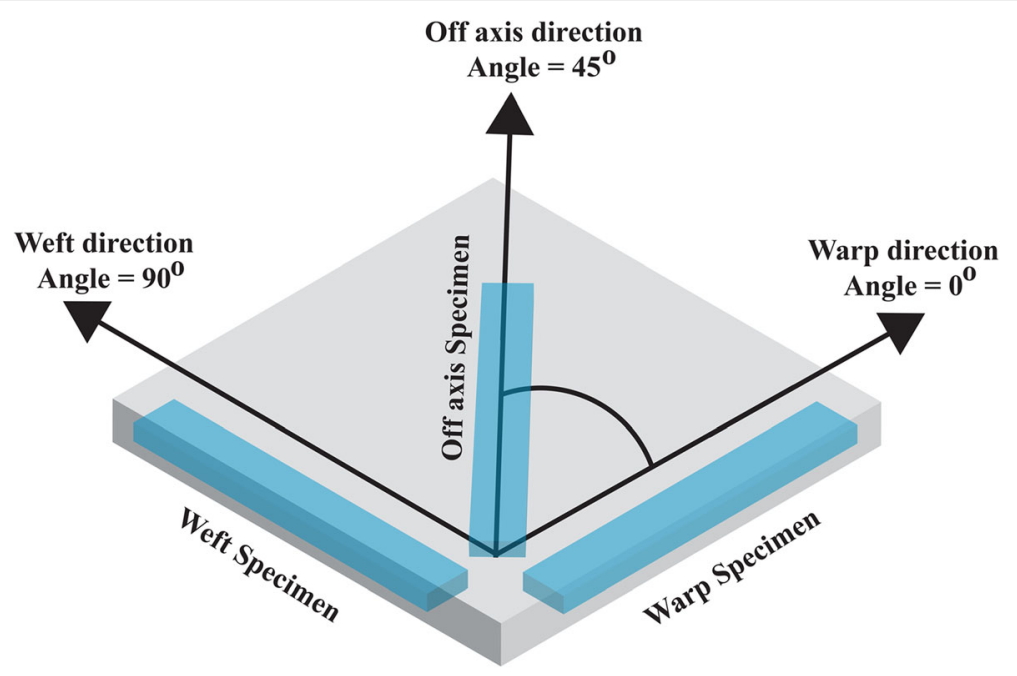

Fig. 3 Schematic of specimens' cutting orientation for in-plane testing

the warp and weft directions. Moreover, compression tests were conducted using the IITRI test fixture, shear using Iosipescu fixture and bending using four-point fixture. The stress-strain response for all the conducted testing and for the various textile architectures was analysed and the fractured surfaces were investigated. Linear stress-strain response was reported when loaded along the warp and weft directions while non-linear response was observed in the case of shear/off-axis loading. The study concluded that resin rich regions and tow-matrix debonding at the interface represented the weak and preferential path for fracture.

For ORT woven composites manufactured out of glass fibre (Ivanov et al. 2009; Lomov et al. 2009) or carbon fibre (Lomov et al. 2011; Bogdanovich et al. 2013), they studied their mechanical response in tension as well as damage initiation and progression using acoustic emission (AE) method both in the warp and weft directions. For the glass fibre case, a comprehensive comparison between ORT woven composite and a 2D plain woven counterpart was conducted. The study suggested that ORT woven composite had significantly higher ultimate tensile strength and strain to failure. This superior response demonstrated the capability of the ORT woven composite in supressing delamination and damage tolerance as opposed to the 2D laminated composites manufactured out of the same fibre type. The study was also supplemented with full-strain maps using DIC analysis and micrographs to visualise damage and cracking progression. In addition, light transparent images were used to trace the damage progression throughout the mechanical test. In the case of carbon fibre ORT woven composite, the "as manufactured" internal geometry was scanned using X-ray CT to reveal any fabric distortion or voids due to the manufacturing process. The X-ray $\mathrm{CT}$ technique was then used to reveal the crack propagation and damage progression during testing. A clear classification of the different types of damage mechanisms observed was tabulated in the study which was supported by the micrographs or the X-ray CT scans (see Table 1 ).

The AE data suggested that the damage progression in the case of warp loading is significantly different from the case of weft loading. The higher energy events in the weft loading direction was attributed to the higher amount of transverse cracking and local debonding as well as the presence of undulated weft yarns on the surface layers of the composite. For the warp loaded ORT woven composite in both studies, it was found that damage initiates firstly at binder interlacement points. It is then followed by transverse cracks in yarns transverse to the loading direction and local delamination between yarns. Final failure is characterised by fibre failure that leads to complete rupture of the specimen.

Table 1 Nomenclature of damage types in on-axis tension test based on (Lomov et al. 2011a)

\begin{tabular}{lll}
\hline Code & Damage type & Direction \\
\hline B & $\begin{array}{l}\text { Cracks on the boundary } \\
\text { of the yarns } \\
\text { Transverse cracking within yarns }\end{array}$ & $\begin{array}{l}\text { Normal to the loading } \\
\text { direction } \\
\text { Normal to the loading } \\
\text { direction }\end{array}$ \\
L & Debonding on yarns' surface & $\begin{array}{l}\text { Parallel to the loading } \\
\text { direction }\end{array}$ \\
MT & $\begin{array}{l}\text { Cracks on the boundary of } \\
\text { Z-binding yarns }\end{array}$ & $\begin{array}{l}\text { Following the Z-binding } \\
\text { yarns surface }\end{array}$ \\
ML & $\begin{array}{l}\text { matrix pockets } \\
\text { Longitudinal cracking in the }\end{array}$ & $\begin{array}{l}\text { Normal to the loading } \\
\text { direction } \\
\text { Parallel to the loading } \\
\text { direction }\end{array}$ \\
\hline
\end{tabular}


In an attempt to highlight the knowledge gap for through-thickness reinforced composites, Mouritz and Cox (Mouritz and Cox 2010) surveyed the available literature to determine the effect of stitching, pinning and 3D weaving (ORT and AI) on the quasi-static (tension, compression, interlaminar shear) and fatigue response of composite materials. According to their study, through-thickness reinforcement either by z-binding yarns or stitching could improve the in-plane mechanical properties but not pinning. For pinning, the reduction of the in-plane properties was justified by the fact that fibre breakage/damage is more prevalent in pinned composites compared to 3D woven and stitched composites, although the percentage of fibres broken by pinning has never been measured. For z-binding and stitching, the enhancement in in-plane mechanical properties have been found to be typically less than $20 \%$ of their equivalent 2D laminate counterparts and independent from the fibre volume fraction or the size of the z-binding yarns/ stitches. On the contrary, some other researchers reported a reduction in the in-plane mechanical properties of 3D woven/ stitched composites which is usually less than $20 \%$ as well. Mouritz and Cox tried to explain this contradiction in the reported data from different researchers. They justified the improvement in the mechanical properties by higher fibre volume fraction due to compaction of the $3 \mathrm{D}$ woven/stitched composites during the throughthickness reinforcement process. However, such an explanation could not be supported without correlating the inplane mechanical properties to the fibre volume fraction and prove repeatability; which is something many researchers failed to report in their studies. On the contrary, the reduction of the in-plane mechanical properties could be attributed to the geometrical distortions and induced defects because of the through-thickness reinforcing process such as fibre waviness, undulation, voids and resin rich regions. Comprehensive quantitative analysis of the effect of defects on the mechanical properties and damage mechanisms of through-thickness reinforced composites is essential to understand the behaviour of such material systems; which according to their study represents a knowledge gap that limits the possibility of predicting the failure strength of 3D woven and stitched composites.

Gerlach et al. (Gerlach et al. 2012) studied AI woven composites, with two different $\mathrm{z}$-binder volume fractions 3 and $6 \%$, subjected to quasi static $\left(3-4 \times 10^{-3} \mathrm{~mm} \cdot \mathrm{s}^{-1}\right)$, medium $\left(85 \mathrm{~mm} \cdot \mathrm{s}^{-1}\right)$ and high $\left(11,000 \mathrm{~mm} \cdot \mathrm{s}^{-1}\right)$ strain rates. The different loading conditions included tension (warp, weft), interlaminar shear, out-of-plane tension and compression, 3-point bending and plate bending. The paper tackled various challenges faced during testing such as developing appropriate test methods for out-of-plane properties characterisation of 3D woven composites as well as the scale effect when comparing the specimen's dimensions required for quasi-static and dynamic "medium/ high strain-rate" tests. Damage evolution for the different conducted tests was characterised with an air-coupled Ultrasound system, X-ray CT system and 3D optical microscopy system. A summary of the experimental campaign and specimens' dimensions is detailed in Table 2. The reader is referred to the original paper for detailed experimentation procedure.

The study concluded that the effect of $\mathrm{z}$-binder volume fraction on the in-plane properties was minor. However, it significantly affects the delamination resistance in the case of plate bending. The paper provided some guidelines for modelling of 3D woven composites, based on a comprehensive experimental campaign, which included accurate modelling of the $\mathrm{z}$-binder deformation and damage propagation as well as its effect on the delamination resistance of the 3D woven composite. Visrolia and Meo (Visrolia and Meo 2013) performed on-axis tension ( $0^{\circ}$ direction), offaxis tension ( $45^{\circ}$ direction) and compression tests to validate their modelling strategy for ORT woven composites. A good agreement of global stress/strain was demonstrated between their proposed model and the experimental results, although for off-axis tension the experimental results were reported up to 3\% strain only (not until failure) and the damage mechanisms were not revealed.

The influence of fabric architecture of 3D woven composite on tensile, compressive and bending response was investigated by Dai et al. (Dai et al. 2015a) only along the warp direction. They focused mainly on ORT and AI architectures while varying the ORT pattern as 1-by-1 and 3-by-3 weaves. Burn-off method was carried out to determine the fibre volume fraction for all the six tested architectures. In addition, DIC was used during tensile loading to visualise the strain map on the surface while optical microscopy was used to reveal the quality of the "as manufactured" panels as well as the damage at failure. They found that the mechanical performance was affected by resin rich regions and waviness of load-carrying fibres. The warp tow waviness measured for the different architectures was in the range of $(0.5$ to $\sim 3 \%)$. The less waviness in a specific architecture, the higher the modulus and strength measured experimentally. The reader is referred to the original paper for detailed analysis. Moreover, one of their AI architecture outperformed

Table 2 Summary of the experimental testing carried out by (Gerlach et al. 2012)

\begin{tabular}{lll}
\hline Test type & Specimen geometry & Specimen dimensions \\
\hline In-plane tension & Dog-bone & $70 \times 10$ \\
Out-of-plane tension & Cross & $20 \times 20$ \\
Shear & Notched beam & $25 \times 20$ \\
Out-of-plane compression & Cube & $10 \times 10$ \\
3-point bending & Prism & $60 \times 10$ \\
Plate bending & Plate & $100 \times 100$ \\
\hline
\end{tabular}


other architectures for all loading conditions "tension, compression and flexure", but it experienced the longest crack delamination. Authors concluded that the delamination length can be reduced by changing the binding sequence to one with shorter binder spacing/ smaller unit cell size. No results along the weft direction or the off-axis direction were reported in this study.

Warren et al. (Warren et al. 2015a) characterised the global stress-strain curves and failure modes of 3D twill harness ORT woven composites, two types of LTL woven composites and 2D quasi-isotropic woven architecture subjected to warp and weft tensions. Optical microscopy images revealed the "as manufactured" internal architecture of the various 3D woven composites in this study. Full field strain mapping up to failure was captured using DIC. Results from DIC clearly showed the higher strain concentrations in the matrix regions especially when loaded along the weft direction; however no explanation for this observation was provided. In case of LTL, a nonlinear stress-strain response was observed and it was attributed to the higher crimp in the warp direction compared to the weft direction. A similar non-linear trend in tension was also reported in (Callus et al. 1999; Leong et al. 2000; Rudov-Clark 2007; Labanieh et al. 2017). Inplane shear testing was also carried out using V-notched rail shear method, where authors found that the shear among adjacent tows and matrix degradation were the dominant damage mechanisms in shear leading to final failure. The effect of crimp on the compressive response was determined by defining the compressive warp-loaded strength/stiffness normalised by the weft-loaded strength/ stiffness. The tow waviness ratio was defined as the tow waviness in the weft tows divided by the tow waviness in the warp tows. Authors suggested that tow waviness has a significant effect on the mechanical performance of 3D LTL woven composites and adjusting tension during the weaving process can be controlled in the weft direction to adjust this tow waviness ratio and keep it closer to unity.

One recent paper by Saleh et al. (Saleh et al. 2016b) characterised the mechanical properties and the influence of the z-binder of three different architectures of 3D woven composites (ORT, LTL, AI) both in the on-axis and off-axis directions. In this study, resin film infusion (RFI) process (see Fig. 4) was utilised to wet the 3D woven fabrics to produce the $3 \mathrm{D}$ woven composite plates.

The study suggested that the z-binder affects void content in 3D woven composites since the amount of resin flowing between warp and weft tows is partly inhibited by the binders. As the RFI process does not have a flow medium to guide the resin during the infusion process, the z-binding yarns in $3 \mathrm{D}$ woven composites guide the resin through the thickness of the 3D preform. Thus, ORT architecture induced the highest amount of void ( 2.63\%) followed by AI $(\sim 2.42 \%)$ and LTL $(\sim 1.63 \%)$ architectures as shown in Fig. 5.
The study also concluded that regardless of the weaving architecture, the directional fibre volume fraction of the warp and weft directly affects the stiffness (Fig. 6a) and tensile strength (Fig. 6b) of 3D woven composites under on-axis loading. For instance, LTL architecture had the highest fibre volume fraction in the weft direction; so it demonstrated the highest modulus and strength along the weft direction out of all the tested architectures. For the sake of comparison between the weft and warp responses/moduli in the light of the directional fibre volume fraction, the maximum difference was clear in the case of LTL $\left(\frac{E_{\text {weft }}}{E_{\text {warp }}} \sim 1.42\right)$ while it was less sound in the case of ORT $\left(\frac{E_{\text {weft }}}{E_{\text {warp }}} \sim 1.23\right)$ and almost vanished for AI $\left(\frac{E_{\text {weft }}}{E_{\text {warp }}} \sim 0.98\right)$.

One of the latest studies by (Castaneda et al. 2016) focused on the tensile response of ORT architecture along the warp/weft directions with the aim to understand the effect of the z-binder on the mechanical response and damage initiation as well as evolution coupled with DIC, $\mathrm{AE}$ and $\mathrm{X}$-ray $\mathrm{CT}$ techniques. Both monotonic and fatigue uniaxial tension cases were studied. Using the DIC system, extensive strain localisation regions, corresponding to higher strain, were captured at the " $\mathrm{z}$-crown" regions and the weft boundaries when loaded along the weft and warp directions respectively. The " $\mathrm{z}$-crowns" were defined as short surface segments of $\mathrm{z}$ yarns oriented in warp direction and laying over the weft yarns. These in-plane strain localisations were successfully correlated with the $\mathrm{AE}$ events. Beside the in-plane strain localisations, out-of-plane strains "jumps" occurred locally at the "z-crown" spots which were associated with both local and global damage progression. Cross sectional X-ray CT scans revealed the most dominant damage mechanisms which were classified as surface tow debonding, surface tow transverse cracking and inner tow debonding. The local surface tow debonding and transverse cracking were referred to as the cause of the local jump of the "z-crowns". The study concluded that although the z-binders could cause out-of-plane effects/deformation, they could still provide transverse reinforcement to $3 \mathrm{D}$ woven composites.

It is worth mentioning at this point that some of the work (Ivanov et al. 2009; Lomov et al. 2009; Bogdanovich et al. 2013; Visrolia and Meo 2013; Saleh et al. 2016b) discussing the on-axis testing has also investigated the offaxis biased loading of 3D woven composites as it will be detailed in the following section.

\section{Off-axis}

Limited work has been performed to characterise 3D woven composites under off-axis $\left(45^{\circ}\right)$ loading direction. As mentioned earlier in the On-axis section, Lomov et al. (Ivanov et al. 2009; Lomov et al. 2009) have reported 

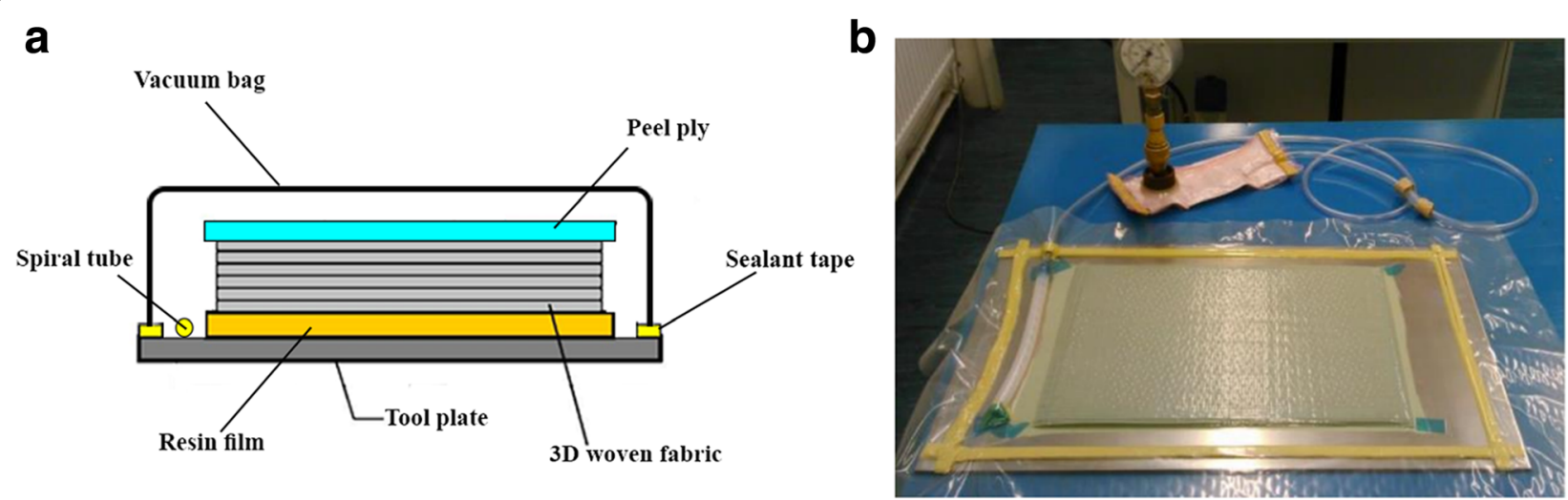

Fig. 4 Resin Film Infusion to manufacture 3D woven composite panels by Saleh et al.: (a) Schematic and (b) vacuum bag layup

loading direction sensitivity (warp, weft, bias) of 3D woven composites but the materials were limited to ORT architecture. The focus on ORT architecture was justified by the fact that this type of architecture could demonstrate higher in-plane stiffness and strength than AI architecture owing to having more straight yarns in the plane of loading. The study also compared the damage evolution of ORT against 2D laminated composite. In addition, it was supplemented with full-strain maps using DIC analysis and micrographs to visualise damage and cracking progression. Clear distinction between the damage evolution in 2D and 3D woven composites was reported. In the case of 2D laminate, damage started in the form of transverse cracks within both the warp and weft yarns. These transverse cracks multiply up to a saturation stage at which local delamination at crack tips was observed. Closer to failure, extensive delamination and "scissoring" effect due to warp and weft realignment led to large shear stresses/strains. Damage for ORT architecture was first observed at the interlacement points with the binder which was referred to in the paper as "z-crown" regions. This type of damage was described as repeated small micro-cracks homogenously distributed across the specimen. They acted as "trellis hinges" around which the warp and weft yarns try to rotate/realign. Afterwards, those cracks penetrated to the matrix pockets forming shear cracks in the neighbouring $\mathrm{z}$ yarns. Then, several shear cracks within the warp and weft yarns were observed before reaching the state of extensive transverse cracking and local debonding between in-plane yarns close to final failure.

Following this work, the study by (Saleh et al. 2016b) has demonstrated the need to determine the loading direction sensitivity of various architectures of 3D woven composites subjected to warp, weft and bias loadings. The relationship between damage mechanisms and energy absorption up to failure was revealed. In addition to investigating the on-axis loading direction response as highlighted in the previous section, the study conducted a detailed examination of the off-axis response of three different 3D woven architectures namely ORT, LTL and AI. X-ray CT technique was used to characterise damage initiation and evolution during testing. The off-axis stress-strain response demonstrated that out of all the tested architectures, ORT exhibited the best performance in terms of the highest failure strength and failure strain as opposed to AI and LTL (see Table 3).

Capturing the damage evolution in the off-axis direction using X-ray CT scans helped in understanding the reason behind the different response of the ORT, LTL and AI architectures. The study used the nomenclature listed in Table 4 to easily describe the various damage mechanisms observed.
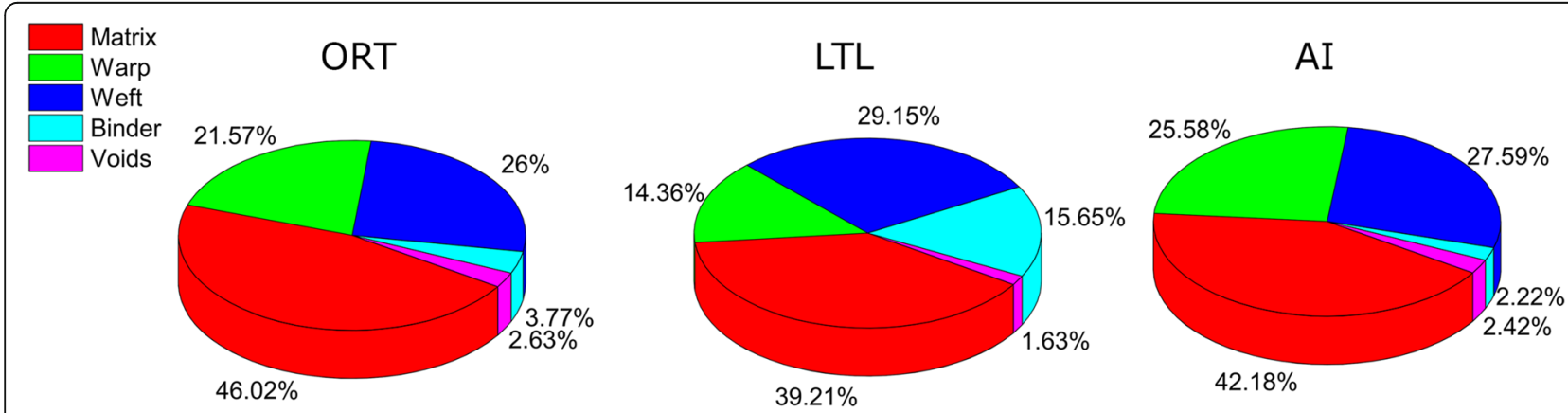

Fig. 5 Results of the volume fraction analysis measured experimentally by (Saleh et al. 2016c) 

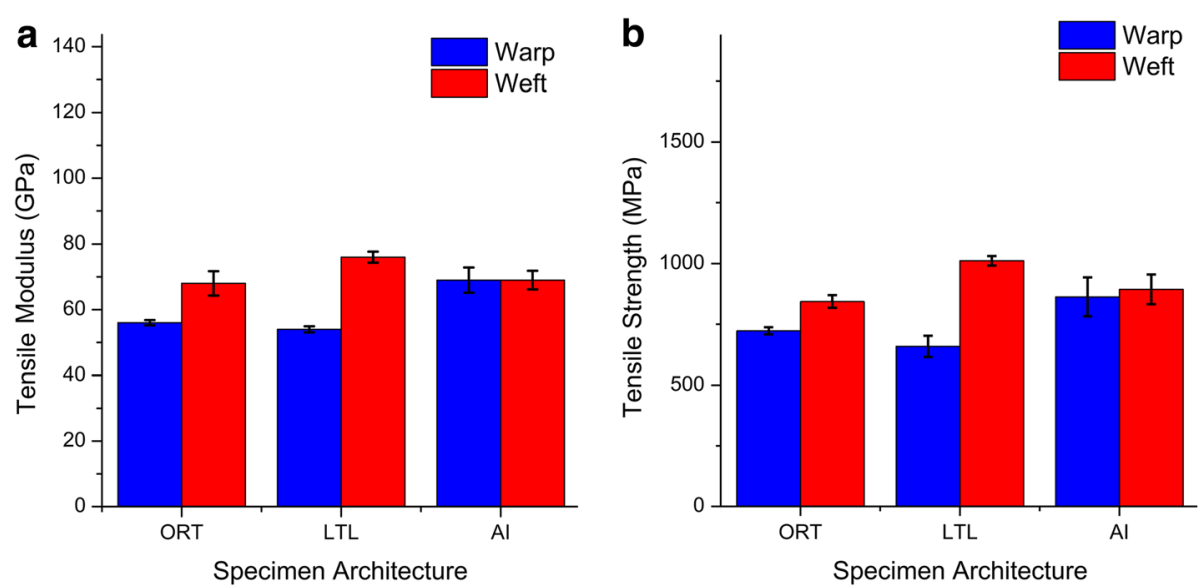

Fig. 6 On-axis tensile properties along the warp and weft directions based on results from (Saleh et al. 2016c): (a) Tensile modulus, (b) Tensile Strength

For all the tested architectures damage initiated in the form of free edge matrix cracking (F-type) due to the interlaminar stresses between layers which was referred to by (Sun and Chu 1991; Mittelstedt and Becker 2004, 2007) as the free edge-effect. This type of damage was then followed by z-binder induced damage (Z-type) in the form of matrix cracking, specifically in ORT and AI, and transverse cracking within yarns (T-type) started multiplying in number before reaching the saturation stage and leading to inter-yarn delamination (D-type) at the crack tips. Inter-yarn delamination continued to grow, guided by the z-binder path, mainly in the LTL case while it got arrested by the z-binding yarns in ORT and AI. Closer to fracture, extensive delamination led to slippage between in-plane yarns (S-type) in the case of AI and LTL. On the contrary, the damage was uniformly distributed all over the gauge length of the ORT specimens. The study attributed this to ORT having a smaller unit cell size and higher z-binder frequency through the thickness. This enabled stress redistribution over a longer span and prevented slippage between the in-plane yarns. Moreover, it helped to create an interlocking mechanism that increased the rotation angle and realignment of the in-plane yarns in the case of ORT and therefore the capability of yarns to experience extensive off-axis strain. With regards to the energy absorption capability, the study concluded that the in-plane off-axis tensile loaded 3D woven composites, in general, can absorb higher amounts of energy compared to their on-axis counterparts. But more interestingly, the

Table 3 Off-axis tensile strength and failure strain of 3D woven composites Off-axis based on (Saleh et al. 2016c)

\begin{tabular}{lll}
\hline Textile architecture & Tensile strength $(\mathrm{MPa})$ & Failure strain $(\%)$ \\
\hline ORT & $237.37 \pm 1.60$ & $22.99 \pm 1.43$ \\
LTL & $135.73 \pm 5.47$ & $11.6 \pm 0.23$ \\
$\mathrm{Al}$ & $173.30 \pm 3.99$ & $12.81 \pm 0.97$ \\
\hline
\end{tabular}

ORT off-axis loaded architecture exhibited the highest energy absorption (3 times higher and five times higher) of all the architectures in the off-axis and the on-axis directions respectively.

Labanieh et al. (Labanieh et al. 2017) recently studied the effect of adding two layers of biased $\left(+\theta^{\circ} /-\theta^{\circ}\right)$ yarns to a classical ORT architecture on the mechanical response in tension and short beam testing. Three ORT architectures were experimentally tested, two of which included the biased in-plane yarns while the last one represented a classical ORT architecture for baseline comparison. In-plane yarns were glass fibre yarns while the binder yarns were Kevlar yarns. The two multiaxial ORT architectures were different from the stacking sequence point of view. One of them (referred to as IMA) had the biased layers $\left(+\theta^{\circ} /-\theta^{\circ}\right)$ adjacent to each other while they were separated by a $0^{\circ}$ layer in the second architecture (referred to as MA). So from the testing point of view, off-axis yarns experienced biaxial stress state when the global loading direction was along the warp or the weft. The "as manufactured" internal microstructure was examined by optical microscopy at different sections and fibre volume fraction was determined experimentally ( $50 \%)$. During testing, full strain mapping was captured with DIC for monotonic and "loading/unloading" tension. In the case of off-axis loading, a significant difference was observed between the multiaxial ORT specimens and the classical ORT. Classical ORT stress-strain response

Table 4 Nomenclature of damage types in off-axis tension test based on (Saleh et al. 2016c)

\begin{tabular}{ll}
\hline Code & Damage type \\
\hline $\mathrm{F}$ & Free edge matrix crack between yarns \\
$\mathrm{Z}$ & Z-binder induced damage \\
$\mathrm{T}$ & Transverse crack within yarns \\
$\mathrm{D}$ & Inter-yarn matrix delamination \\
$\mathrm{S}$ & Slippage between in-plane tows "warp/weft" \\
\hline
\end{tabular}


was significantly non-linear compared to the two multiaxial counter parts with much higher strain to failure and much lower strength. This distinguished behaviour of the classical ORT was attributed to the absence of reinforcing fibres along this off-axis $\left(45^{\circ}\right)$ loading direction. Modulus degradation due to damage evolution was measured through the "loading/unloading" tensile test in the warp, weft and off-axis direction and recommended by the authors for incorporation in modelling the effect of damage in 3D woven composites. The reader is referred to the original article for extensive discussion of ILSS data of the specified architectures.

\section{Notched characterisation Open-hole tension On-axis}

The scope of previous studies in the literature has been dedicated to evaluating the effect of notches on the strength, fracture toughness, damage and failure mechanisms of both laminated (Awerbuch and Madhukar 1985; Callus 2007) and 2D woven composites (Yudhanto et al. 2012a, b). It was observed that the undulating nature of the woven fabric improves the delamination and splitting resistance compared to $2 \mathrm{D}$ laminates as it helped in preventing crack propagation within the matrix and acted as crack stoppers. Thus, the notched strength of the $2 \mathrm{D}$ woven laminates was reported to be higher than the laminated composites. In other words, 2D woven composites were found to be less notch sensitive (Naik et al. 1990; Shembekar and Naik 1992). Replacing 2D with 3D woven composites helped in achieving further enhancement of the notched strength and fracture toughness, along the fibre direction, of composites as reported in (Cox et al. 1996; Tsai et al. 2000). The effect of the through-thickness binder in 3D woven composites was clearly observed as a dramatic decrease in the notch sensitivity of 3D woven composites and significant improvement of the fracture toughness and damage tolerance compared with those of 2D woven laminates.

Recently, Dai et al. (Dai et al. 2015b), investigated the notch sensitivity of carbon fibre reinforced polymers (CFRP) ORT and AI woven composites tested in quasistatic tension and tension-tension fatigue. The scope of both tests was the on-axis loading either along the warp or the weft direction. For quasi-static testing, DIC was used to monitor the damage evolution up to failure while an infra-red camera was used in the case of fatigue testing to monitor the development of fatigue damage. To address the effect of the notch size on the notched response of 3D woven composites, two hole sizes with a diameter to width ratio of $1 / 6$ and $1 / 2$ respectively were tested. The study concluded that regardless of the hole size, the reduction in the strength of the investigated architectures did not exceed 17\% compared to the un-notched strength in the case of on-axis loading. Although 3D woven composites tested along the warp or weft directions have been proven to be relatively notch insensitive (Mubeen 2014; Dai et al. 2015b), there is very limited literature reporting the behaviour/sensitivity of 3D woven composites loaded along the off-axis direction exists.

\section{Off-axis}

Only one recent study by Saleh et al. (Saleh et al. 2016a) reported the notched response of 3D woven composites, in off-axis orientation, by an open hole tension test. The study considered three different architectures namely ORT, AI and LTL and focused only on the off-axis direction. DIC was used for in-situ damage evolution monitoring as shown in the test setup (Fig. 7).

As a measure of the notch sensitivity, the normalised tensile strength was defined as the notched strength $\left(\sigma_{n}\right)$ divided by the un-notched strength $\left(\sigma_{u n}\right)$. For all the tested architectures, the normalised tensile strength was greater than $90 \%$, which suggested that all the tested architectures

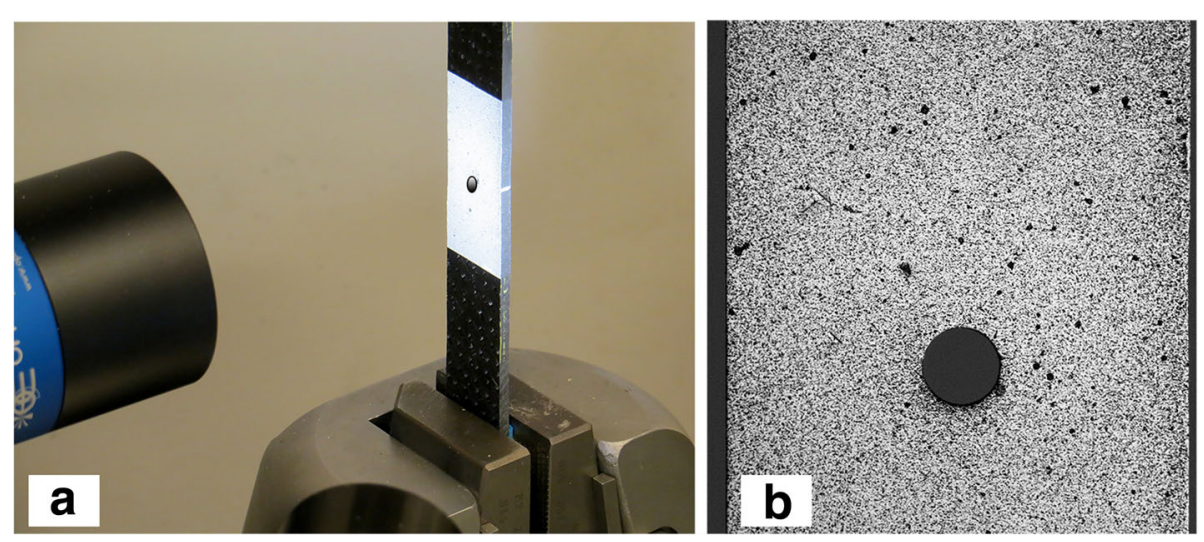

Fig. 7 Open hole: (a) Test setup "hole has been highlighted for clarification", (b) Speckle pattern for DIC (Saleh et al. 2016b) 
were relatively notch insensitive (see Table 5) compared to the ideally ductile "notch insensitive" curve defined in Eq. 1.

$$
\sigma_{n} / \sigma_{u n}=1-(d / w)
$$

where:

$\left(\sigma_{n}\right)$ : The notched tensile strength

$\left(\sigma_{u n}\right)$ : The un-notched tensile strength

$(d)$ : The hole diameter

$(w)$ : The specimen width

The final failure of the 3D woven architectures "corresponding to $40 \%$ load drop during testing" in the off-axis direction was progressive failure not catastrophic brittle fracture. Moreover, the ORT architecture in the off-axis orientation, out of all the tested architectures, exhibited higher ultimate strength and strain to failure, as was the case for the un-notched specimens reported in (Saleh et al. 2016b). The difference in the response for the ORT was attributed to the high density/frequency of the through-thickness binding which acted as crack stoppers for delamination and matrix cracking. In addition, the DIC analysis highlighted that the ORT architecture redistributed the stress/strain over a wider region away from the hole which reduced the stress concentration at the notch periphery (see Fig. 8) compared to the AI and LTL architectures which failed prematurely at a $45^{\circ}$ line due to extensive delamination.

The paper concluded that 3D woven composites in the off-axis orientation, especially ORT, demonstrated a potential of overcoming some of the major challenges for composite joint applications which include the pseudoductility, stress redistribution away from the notch and notch insensitivity.

\section{Bearing strength}

In spite of many studies investigating the bearing response of 2D laminated composites (Kelly and Hallström 2004; Thoppul et al. 2009; Pisano and Fuschi 2011; Atas 2012; Öndürücü et al. 2012; Ataş and Soutis 2013, 2014; Khashaba et al. 2013), the literature discussing the bearing response for 3D woven composites is quite sparse. A study by Warren et al. (Warren et al. 2015b) investigated the bearing response of ORT and LTL 3D woven architectures. Extensive investigation of the single-lap response of these two architectures was carried out with the objective

Table 5 Average un-notched, notched and normalised strength of $3 \mathrm{D}$ woven composites loaded in the off-axis direction

\begin{tabular}{llll}
\hline $\begin{array}{l}\text { Textile } \\
\text { architecture }\end{array}$ & $\begin{array}{l}\text { Un-notched } \\
\text { strength }(\mathrm{MPa})\end{array}$ & $\begin{array}{l}\text { Notched } \\
\text { strength }(\mathrm{MPa})\end{array}$ & $\begin{array}{l}\text { Normalised } \\
\text { strength }\left(\sigma_{n} /\left(\sigma_{\text {un }}\right)\right.\end{array}$ \\
\hline ORT & 237.37 & 215.29 & 0.91 \\
$\mathrm{Al}$ & 173.3 & 172.21 & 0.99 \\
LTL & 135.73 & 128.31 & 0.95 \\
\hline
\end{tabular}

of exploring the dependency of the response on the loading orientation. In order to achieve this, seven different orientations between warp $\left(0^{\circ}\right)$ and weft $\left(90^{\circ}\right)$ directions were tested in quasi-static single-lap test as shown schematically in Fig. 9a. On the contrary, only one single loading orientation along the warp direction was used to study the double-lap bearing response (see Fig. 9b) of the same architectures. In the case of LTL architecture, two sizes of IM7 carbon tows were used; $12 \mathrm{~K}$ and $24 \mathrm{~K}$. For all the tested orientations, the failure of $3 \mathrm{D}$ woven composites was a non-catastrophic failure accompanied by bearing failure mode. Matrix cracking and tow distortion around the hole, which caused some drop in the load were reported as the most dominant damage mechanisms. A stiffness reduction in the range of 24.7 to $32.7 \%$ of the onaxis stiffness was observed upon changing the loading orientation in the single-lap bearing strength test. In addition, the $24 \mathrm{~K}$ tow size increased slightly the bearing response compared to the $12 \mathrm{~K}$ for LTL architecture.

As an attempt to determine the off-axis response of $3 \mathrm{D}$ woven composites, the double-lap bearing strength test (see Fig. 9b) has been conducted for ORT, AI and LTL architectures in the off-axis direction by Saleh et al. (Saleh et al. 2016a). X-ray CT was used to visualise the internal damage of the failed specimens.

Up to $50 \%$ bearing strain, no significant variation in the global bearing stress/bearing strain response (see Fig. 10a) was observed. Summary of the bearing mechanical properties of the ORT, AI and LTL architectures is detailed in Table 6.

Similar to (Warren et al. 2015b), all architectures failed, non-catastrophically, in a bearing failure mode. However, X-ray CT scans revealed the effect of the zbinder path on the damage mechanisms and delamination propagation. The dominant damage mechanisms were found to include matrix crushing, extensive delamination, transverse cracking and z-binder induced damage. When specimens are loaded up to failure, a clear difference in the bearing stress/strain response was observed (see Fig. 10b). The study reported that the ORT architecture in the off-axis direction displayed an enhanced ability to carry higher loads after damage onset until ultimate failure followed by AI and finally LTL which is directly reflected by the energy absorption of ORT being the highest followed by AI and finally LTL. This suggested that in addition to the unit cell size effect, having a through-thickness binder (ORT and AI) can suppress delamination and delay final failure. However, delamination progression is guided by the $\mathrm{z}$ binding yarns between layers which led to final failure of the LTL architecture as proven by the X-ray CT scans.

One recent study by Mounien et al. (Mounien et al. 2016) investigated the on-axis vs. off-axis bearing response of thick 3D woven composites $(9.4 \mathrm{~mm}$ or $19.6 \mathrm{~mm}$ ). This is considered the only study that focuses on thick $3 \mathrm{D}$ 


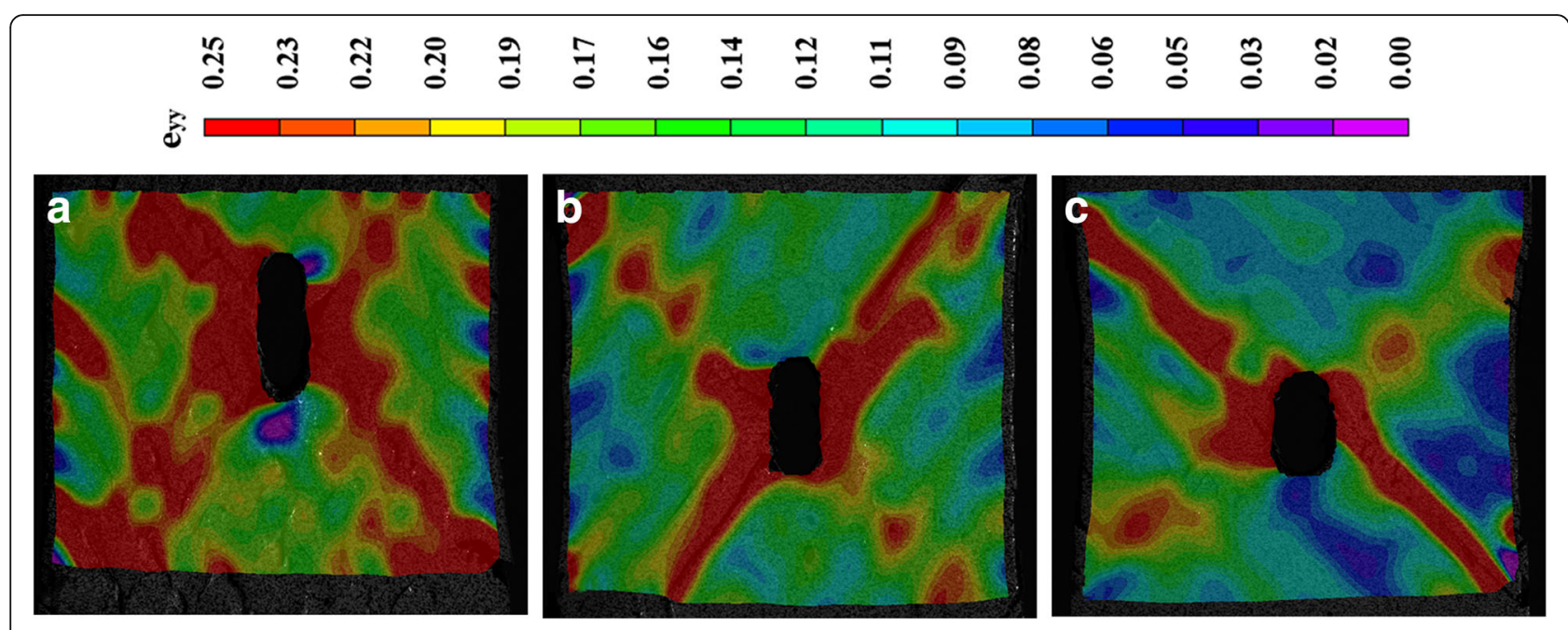

Fig. 8 Strain contour map obtained using DIC at failure based on (Saleh et al. 2016b): (a) ORT, (b) Al, (c) LTL

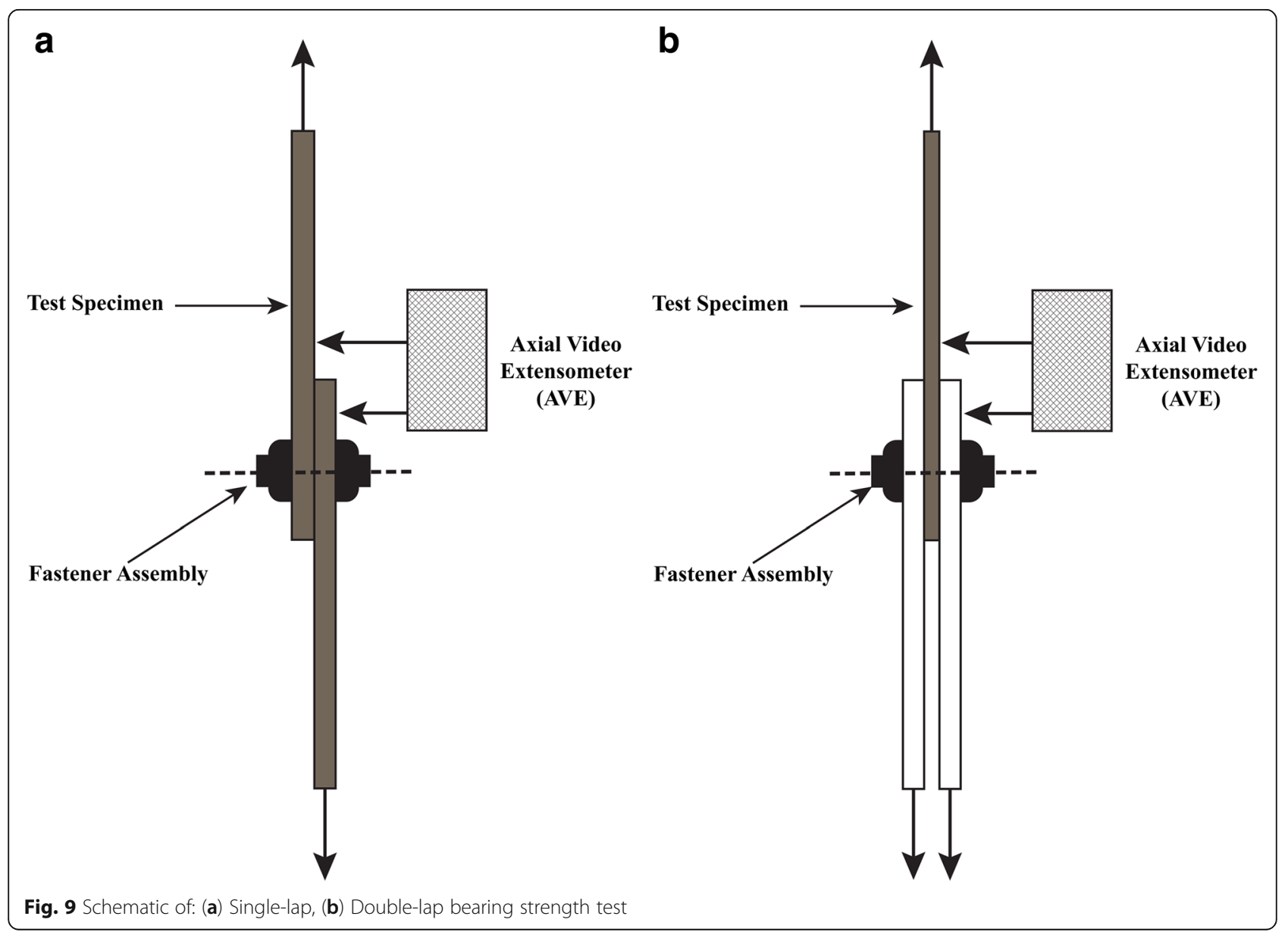



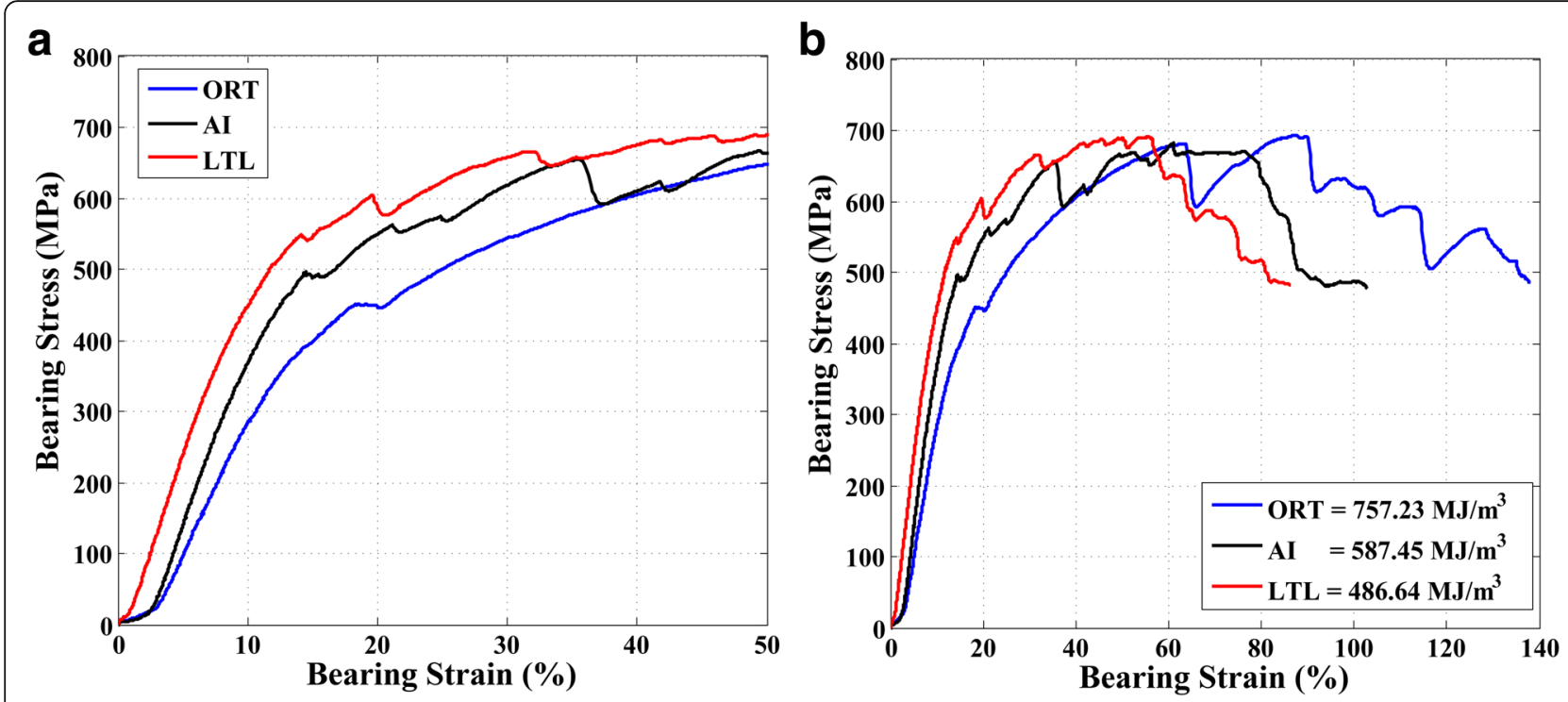

Fig. 10 Double-lap bearing stress-strain curve (Saleh et al. 2016b): (a) Up to 50\%, (b) Up to failure

woven composites as opposed to relatively thinner ones reported by (Warren et al. 2015b; Saleh et al. 2016a). Two tests were conducted namely as the pin-bearing test on half-hole and the double-lap pin-bearing test. The designed 3D woven fabrics were unbalanced with a higher fibre volume fraction in the warp direction compared to the weft direction. However, the authors did not specify the architecture of the 3D woven composite tested in their study. During testing, DIC was used to obtain a full strain maps and $\mathrm{AE}$ was utilised to detect damage initiation and evolution through the accumulated AE energy and the amplitude of the AE events. Authors reported a good agreement between the bearing strength obtained from the half-hole and double-lap tests along the warp and weft directions, but not in the biased "off-axis" direction. This was attributed to the fact that in the half-hole test the load carrying yarns were cut along the cross section for testing. In the case of the double-lap test, the warp-loaded specimens demonstrated the highest stiffness but the off-axis loaded specimens had the highest bearing strength, which supports the argument proposed earlier by (Saleh et al. 2016a) that although off-axis 3D woven composites demonstrate less stiffness, they possess significantly better damage resistance/tolerance capabilities up to failure.

Table 6 Summary of the bearing strength test results based on (Saleh et al. 2016b)

\begin{tabular}{llll}
\hline $\begin{array}{l}\text { Textile } \\
\text { architecture }\end{array}$ & $\begin{array}{l}\text { Bearing } \\
\text { stiffness (GPa) }\end{array}$ & $\begin{array}{l}\text { Offset bearing } \\
\text { strength (MPa) }\end{array}$ & $\begin{array}{l}\text { Ultimate bearing } \\
\text { strength (MPa) }\end{array}$ \\
\hline ORT & $3.48 \pm 0.02$ & $429.63 \pm 57.53$ & $658.67 \pm 27.62$ \\
Al & $5.26 \pm 0.09$ & $456.90 \pm 38.33$ & $683.33 \pm 9.39$ \\
LTL & $5.32 \pm 0.23$ & $466.97 \pm 33.06$ & $677.33 \pm 22.95$ \\
\hline
\end{tabular}

Finally, the study proposed a damage scenario to explain the failure of the on-axis loaded specimens which still needs to be supported by X-ray CT scans. Kinking of the tows at the loaded edge led to the non-linear behaviour observed which then developed through the specimen's thickness forming a network of kink bands, transverse cracks and tows debonding. Once the load-carrying yarns failed by kinking, it led to the bearing failure observed.

\section{Discussion \& concluding remarks}

As the objective of this study was to provide a comprehensive review of recent experimental work characterising the mechanical properties of 3D woven composites, Table 7 classifies most of the papers, to the authors' knowledge, which investigated the un-notched tensile, compressive, inplane shear, interlaminar shear and flexural response depending on the weaving architecture "ORT, LTL or AI". Such a summary was mainly designed to highlight the knowledge gap in literature and point out different types of testing required to fully characterise such material systems ahead of relying on them in real life applications. It is clear from the comparison that ORT architecture has received the most extensive attention specially in characterising the tensile and compressive response. However, less work has been done to characterise the in-plane shear, flexural and interlaminar shear response of ORT, LTL and AI. In real life applications, it is quite uncommon for a component or structure to experience only a single state of stress, so it is quite essential to draw more attention to the lateral types of testing to realistically characterise 3D woven composites in which multiaxial loading conditions are expected.

Similarly, Table 8 attempts to summarise the notch sensitivity characterisation of 3D woven composites as 
Table 7 Summary of the available literature for the un-notched mechanical characterisation of 3D woven composites

\begin{tabular}{|c|c|c|c|c|c|}
\hline & Tension & Compression & $\begin{array}{l}\text { In-plane Shear/ Off-axis } \\
\text { Tension }\end{array}$ & Flexural & ILSS \\
\hline ORT & $\begin{array}{l}\text { (Cox et al. 1994; Callus } \\
\text { et al. 1999; Leong et al. } \\
\text { 2000; Wang 2006; Quinn } \\
\text { et al. 2008; Lomov et al. } \\
\text { 2009, 2011b; Tong et al., } \\
\text { 2009b; Mouritz and Cox } \\
\text { 2010; Bogdanovich et al. } \\
\text { 2013; Visrolia and Meo } \\
\text { 2013; Muñoz et al. 2014; } \\
\text { Nasution et al. 2014; } \\
\text { Green et al. 2014; Behera } \\
\text { and Dash 2015; Warren } \\
\text { et al. 2015a; Dai et al. } \\
\text { 2015a; Saleh et al. 2016c; } \\
\text { Castaneda et al. 2016; } \\
\text { Labanieh et al. 2017) }\end{array}$ & $\begin{array}{l}\text { (Cox et al. 1994; Mouritz } \\
\text { et al. 1999a; Wang 2006; } \\
\text { Tong and Mouritz MB } \\
\text { 2009b; Lomov et al. } \\
\text { 2009; Mouritz and Cox } \\
\text { 2010; Visrolia and Meo } \\
\text { 2013; Behera and Dash } \\
\text { 2015; Warren et al. } \\
\text { 2015a; Dai et al. 2015a; } \\
\text { Turner et al. 2016) }\end{array}$ & $\begin{array}{l}\text { (Lomov et al. 2009; } \\
\text { Bogdanovich et al. 2013; } \\
\text { Visrolia and Meo 2013; } \\
\text { Warren et al. 2015a; } \\
\text { Saleh et al. 2016c; } \\
\text { Labanieh et al. 2017) }\end{array}$ & $\begin{array}{l}\text { (Chou et al. 1992; Cox } \\
\text { et al. 1994; Wang 2006; } \\
\text { Tong et al., 2009b; } \\
\text { Nasution et al. 2014; } \\
\text { Behera and Dash 2015; } \\
\text { Dai et al. 2015a) }\end{array}$ & $\begin{array}{l}\text { (Wang 2006; Tong et al., } \\
\text { 2009b; Mouritz and Cox } \\
\text { 2010; Walter et al. 2010; } \\
\text { Labanieh et al. 2017) }\end{array}$ \\
\hline $\mathrm{Al}$ & $\begin{array}{l}\text { (Cox et al. 1994, 1996; } \\
\text { Pochiraju 1999; Tong } \\
\text { et al., 2009b; Mouritz } \\
\text { and Cox 2010; Gerlach } \\
\text { et al. 2012; Mubeen } \\
\text { 2014; Behera and Dash } \\
\text { 2015; Yu et al. 2015a; } \\
\text { Dai et al. 2015a; Saleh } \\
\text { et al. 2016c) }\end{array}$ & $\begin{array}{l}\text { (Cox et al., 1994; } \\
\text { Pochiraju 1999; Tong } \\
\text { et al., 2009b; Mouritz } \\
\text { and Cox 2010; Behera } \\
\text { and Dash 2015; Dai et al. } \\
\text { 2015a) }\end{array}$ & $\begin{array}{l}\text { (Pochiraju 1999; } \\
\text { Buchanan et al. 2012; } \\
\text { Saleh et al.2016c) }\end{array}$ & $\begin{array}{l}\text { (Cox et al. 1994; Tong } \\
\text { et al., 2009b; Mouritz } \\
\text { and Cox 2010; Yang } \\
\text { et al. 2014; Behera and } \\
\text { Dash 2015; Dai et al. } \\
\text { 2015a; Umer et al. 2016) }\end{array}$ & $\begin{array}{l}\text { (Tong et al., 2009b; } \\
\text { Mouritz and Cox 2010; } \\
\text { Walter et al. 2010) }\end{array}$ \\
\hline LTL & $\begin{array}{l}\text { (Cox et al. 1994, 1996; } \\
\text { Callus et al. 1999; } \\
\text { Pochiraju 1999; Stig and } \\
\text { Hallström 2009; Mubeen } \\
\text { 2014; Warren et al. } \\
\text { 2015a; Yu et al. 2015a; } \\
\text { Saleh et al. 2016c) }\end{array}$ & $\begin{array}{l}\text { (Cox et al., 1994; Mouritz } \\
\text { et al. 1999b; Stig and } \\
\text { Hallström 2009; Mahadik } \\
\text { and Hallett 2011; Dai } \\
\text { et al. 2015a; Warren } \\
\text { et al. 2015a) }\end{array}$ & $\begin{array}{l}\text { (Pochiraju 1999; Warren } \\
\text { et al. 2015a; Saleh et al. } \\
\text { 2016c) }\end{array}$ & $\begin{array}{l}\text { (Cox et al. 1994; Umer } \\
\text { et al. 2016) }\end{array}$ & $\begin{array}{l}\text { (Stig and Hallström } \\
\text { 2009) }\end{array}$ \\
\hline
\end{tabular}

well as the impact response discussed in the literature. One of the major challenges facing the expansion of using composite materials in application is the notch effect. However, it is clear from the comparison that there is very little work focused on understanding the notched behaviour of 3D woven composites either loaded along the fibre direction "warp/weft" or along a biased "offaxis" direction. On the other hand, a fair amount of work has been performed to characterise the impact

Table 8 Summary of the available literature for the notched and impact mechanical characterisation of 3D woven composites

\begin{tabular}{|c|c|c|c|}
\hline & Open-hole & $\begin{array}{l}\text { Bearing } \\
\text { Strength }\end{array}$ & Impact/Indentation \\
\hline ORT & $\begin{array}{l}\text { (Dai et al. } \\
\text { 2015b; Saleh } \\
\text { et al. 2016b) }\end{array}$ & $\begin{array}{l}\text { (Warren et al. } \\
\text { 2015b; Saleh } \\
\text { et al. 2016b) }\end{array}$ & $\begin{array}{l}\text { (Baucom and Zikry 2003; Ji } \\
\text { et al. 2007; Luo et al. 2007; } \\
\text { Hao et al. 2008; Potluri et al. } \\
\text { 2012; Seltzer et al. 2013; } \\
\text { Umer et al. 2016) }\end{array}$ \\
\hline $\mathrm{Al}$ & $\begin{array}{l}\text { (Mubeen 2014; } \\
\text { Dai et al. } \\
\text { 2015b; Saleh } \\
\text { et al. 2016b) }\end{array}$ & $\begin{array}{l}\text { (Saleh et al. } \\
\text { 2016b) }\end{array}$ & $\begin{array}{l}\text { (Gerlach et al. 2012; Potluri } \\
\text { et al. 2012; Mubeen 2014; } \\
\text { Behera and Dash 2015; } \\
\text { Umer et al. 2016; Wang } \\
\text { et al. 2017) }\end{array}$ \\
\hline LTL & $\begin{array}{l}\text { (Mubeen 2014; } \\
\text { Saleh et al. } \\
\text { 2016b) }\end{array}$ & $\begin{array}{l}\text { (Saleh et al. } \\
\text { 2016b) }\end{array}$ & $\begin{array}{l}\text { (Potluri et al. 2012; Mubeen } \\
\text { 2014; Umer et al. 2016; } \\
\text { Elias et al. 2017) }\end{array}$ \\
\hline
\end{tabular}

behaviour of $3 \mathrm{D}$ woven composites that outperforms the impact performance of unidirectional pre-preg based or $2 \mathrm{D}$ woven laminates. The potential of using nondestructive testing (NDT) techniques for damage

Table 9 Summary of the available literature of the NDT techniques used for 3D woven composites

\begin{tabular}{llll}
\hline \multicolumn{1}{c}{ DIC } & AE & X-ray CT \\
\hline ORT & (Ivanov et al. 2009; & (Ivanov et al. 2009; & (Ivanov et al. 2009; \\
& Lomov et al. 2009; & Lomov et al. 2009, & Lomov et al. 2009; \\
Bogdanovich et al. & 2011a; & Bogdanovich et al. \\
2013; Dai et al. & Bogdanovich et al. & 2013; Seltzer et al. \\
2015a, 2015b; & 2013; Li et al. 2014; & 2013; Muñoz et al. \\
Warren et al. 2015a; & Castaneda et al. & 2014; Castaneda \\
Castaneda et al. & 2016) & et al. 2016; Saleh \\
2016; Saleh et al. & & et al. 2016b, c; \\
2016a, c; Labanieh & & Umer et al. 2016) \\
et al. 2017) & & \\
Al & (Mubeen 2014; Dai & (Gresil et al. 2016) & (Gerlach et al. \\
& et al. 2015a, 2015b; & & 2012; Yu et al. \\
& Saleh et al. 2016c) & & 2015b, Yu et al. \\
& & & 2016b, Saleh et al. \\
& & & 2016b, 2016c; \\
& & Umer et al. 2016) \\
LTL & (Mubeen 2014; & Not available & (Yu et al. 2015b, \\
& Warren et al. 2015a; & & Saleh et al. 2016a, \\
& Saleh et al. 2016c) & & Saleh et al. 2016b, \\
& & & c; Umer et al. 2016) \\
\hline
\end{tabular}


detection in 3D woven composites is summarised in Table 9. Several researchers utilised DIC, X-ray CT and $\mathrm{AE}$ techniques to characterise damage in ORT architecture with less focus on $\mathrm{AI}$ and almost minimal attention to LTL. This suggests a room for improvement in establishing such techniques specially $\mathrm{AE}$ as a valuable NDT technique for damage initiation and evolution detection for 3D woven composites.

As a general remark from the reviewed studies, having a through-thickness z-binder (ORT and AI) can suppress delamination and delay final failure. However, in the case of LTL architecture, delamination progression between layers is guided by the z-binding yarns, which leads to final failure. The same effect is observed in the cases of the un-notched, notched and bearing response of 3D woven composites. This suggests that optimisation of 3D woven composites design should consider the z-binder architecture depending on the application and avoid the LTL binding approach. Then, the second optimisation parameter is the z-binder frequency going from top to bottom "unit-cell size". For applications in which high strain to failure and higher energy absorption required, smaller weaving architecture unit-cell with higher zbinder density should be adopted such as the ORT architecture. In conclusion, 3D woven composites have proven that not only they have enhanced out-of-plane properties, but also better damage resistance/tolerance and enhanced in-plane properties when compared to their counterparts of unidirectional pre-preg based or 2D woven laminates.

\section{Abbreviations}

2D: Two-dimensional; 3D: Three-dimensional; AE: Acoustic emission; Al: Angle interlock; CFRP: Carbon fibre reinforced polymers; CT: Computed tomography; DIC: Digital image correlation; FEM: Finite element modeling; ILSS: Interlaminar shear strength; LTL: Layer-to-layer; NDT: Non-destructive testing; ORT: Orthogonal; RFI: Resin film infusion; TT: ThroughthicknessIntroduction

\section{Acknowledgments}

Not applicable.

Funding

Not applicable.

\section{Availability of data and materials}

The data and materials supporting this review are available online as per the cited journal publications and conference proceedings.

\section{Authors' contributions}

MNS: combined the different studies available in the literature and wrote the manuscript. CS: helped in reviewing and editing it. Both authors read and approved the final manuscript.

\section{Competing interests}

The authors declare that they have no competing interest.

\section{Consent for publication}

Not applicable.

Ethics approval and consent to participate Not applicable.

\section{Endnotes}

Not applicable.

\section{Publisher's Note}

Springer Nature remains neutral with regard to jurisdictional claims in published maps and institutional affiliations.

\section{Author details}

${ }^{1}$ Advanced Manufacturing Research Centre with Boeing, University of Sheffield, S60 5TZ, Rotherham, UK. ²Aerospace Research Institute, University of Manchester, M1 3NJ, Manchester, UK.

Received: 27 April 2017 Accepted: 8 June 2017

Published online: 10 July 2017

\section{References}

Ansar M, Xinwei W, Chouwei Z (2011) Modeling strategies of 3D woven composites: a review. Compos Struct 93:1947-1963. doi:10.1016/j.compstruct. 2011.03.010

Atas A (2012) Strength prediction of mechanical joints in composite laminates based on subcritical damage Modelling.

Ataş A, Soutis C (2013) Subcritical damage mechanisms of bolted joints in CFRP composite laminates. Compos Part B Eng 54:20-27. doi:10.1016/j. compositesb.2013.04.071

Ataş A, Soutis C (2014) Strength prediction of bolted joints in CFRP composite laminates using cohesive zone elements. Compos Part B Eng 58:25-34. doi:10.1016/j.compositesb.2013.10.017

Awerbuch J, Madhukar MS (1985) Notched strength of composite Laminates: predictions and experiments \& mdash - a review. J Reinf Plast Compos Reinf 4:3-159. doi:10.1177/073168448500400102

Baucom JN, Zikry MA (2003) Evolution of failure mechanisms in 2D and 3D woven compositesystems under quasi-static perforation. J Compos Mater 37:1651-1674. doi:10.1177/002199803035178

Bayraktar H, Ehrlich D, Goering J, et al. (2015) 3D woven composites for energy absorbing. In: 20th international conference on composite materials. Copenhagen, pp 19-24

Behera BK, Dash BP (2015) Mechanical behavior of 3D woven composites. Mater Des 67:261-271. doi:10.1016/j.matdes.2014.11.020

Bogdanovich AE, Karahan M, Lomov SV, Verpoest I (2013) Quasi-static tensile behavior and damage of carbon/epoxy composite reinforced with 3D noncrimp orthogonal woven fabric. Mech Mater 62:14-31. doi:10.1016/j. mechmat.2013.03.005

Buchanan S, Archer E, Townsend D et al (2012) Determination of in-plane shear modulus of 3D woven composites with large repeat unit cells. Plast Rubber Compos 41:194-198. doi:10.1179/1743289811y.0000000060

Callus PJ (2007) The effects of hole-size and environment on the mechanical behaviour of a quasi-isotropic AS4/3501-6 laminate in tension. Compression Bending Air Veh Div Def Sci Technol Organ:1-82

Callus PJ, Mouritz AP, Bannister MK, Leong KH (1999) Tensile properties and failure mechanisms of 3D woven GRP composites. Compos Part A Appl Sci Manuf 30:1277-1287. doi:10.1016/S1359-835X(99)00033-0

Castaneda N, Wisner B, Cuadra J et al (2016) Investigation of the Z-binder role in progressive damage of 3D woven composites. Compos Part A Appl Sci Manuf 98:76-89. doi:10.1016/j.compositesa.2016.11.022

Chou S, Chen HC, Chen HE (1992) Effect of weave structure on mechanical fracture behavior of three-dimensional carbon fiber fabric reinforced epoxy resin composites. Compos Sci Technol 45:23-35. doi:10.1016/0266-3538(92)90119-N

Cox B, Dadkhah M, Morris W, Flintoff J (1994) Failure mechanisms of 3D woven composites in tension, compression, and bending. Acta Metall Mater. doi:10.1016/0956-7151(94)90174-0

Cox BN, Dadkhah MS, Morris WL (1996) On the tensile failure of 3D woven composites. Compos Part A Appl Sci Manuf 27:447-458. doi:10.1016/1359835X(95)00053-5

Dai S, Cunningham PR, Marshall S, Silva C (2015a) Influence of fibre architecture on the tensile, compressive and flexural behaviour of 3D woven composites. Compos Part A Appl Sci Manuf 69:195-207. doi:10.1016/j.compositesa.2014.11.012

Dai S, Cunningham PR, Marshall S, Silva C (2015b) Open hole quasi-static and fatigue characterisation of 3D woven composites. Compos Struct 131:765774. doi:10.1016/j.compstruct.2015.06.032

Elias A, Laurin F, Kaminski M, Gornet L (2017) Experimental and numerica investigations of low energy/velocity impact damage generated in 3D 
woven composite with polymer matrix. Compos Struct 159:228-239. doi:10. 1016/j.compstruct.2016.09.077

Gerlach R, Siviour CR, Wiegand J, Petrinic N (2012) In-plane and throughthickness properties, failure modes, damage and delamination in 3D woven carbon fibre composites subjected to impact loading. Compos Sci Technol 72:397-411. doi:10.1016/j.compscitech.2011.11.032

Green SD, Matveev MY, Long AC et al (2014) Mechanical modelling of 3D woven composites considering realistic unit cell geometry. Compos Struct 118:284293. doi:10.1016/j.compstruct.2014.07.005

Gresil M, Saleh MN, Soutis C (2016) Transverse Crack Detection in 3D Angle Interlock Glass Fibre Composites Using Acoustic Emission. Materials (Basel). doi:10.3390/ma9080699

Hao A, Sun B, Qiu Y, Gu B (2008) Dynamic properties of 3-D orthogonal woven composite T-beam under transverse impact. Compos Part A Appl Sci Manuf 39:1073-1082. doi:10.1016/j.compositesa.2008.04.012

Hemrick JG, Lara-Curzio E, Loveland ER et al (2011) Woven graphite fiber structures for use in ultra-light weight heat exchangers. Carbon N Y 49:4820 4829. doi:10.1016/j.carbon.2011.06.094

Ivanov DS, Lomov SV, Bogdanovich AE et al (2009) A comparative study of tensile properties of non-crimp 3D orthogonal weave and multi-layer plain weave E-glass composites. Part 2: comprehensive experimental results. Compos Part A Appl Sci Manuf 40:1144-1157. doi:10.1016/j.compositesa. 2009.04.032

Jewell J, Kennedy R, Menard A (2011) Full-scale LEAP Fan Blade-Out Rig Test Yields Outstanding Results; Advanced LEAP Fan Endurance Test Complete. In: CFM Power Flight.

Ji C, Sun B, Qiu Y, Gu B (2007) Impact damage of 3D orthogonal woven composite circular plates. Appl Compos Mater 14:343-362. doi:10.1007/ s10443-008-9050-x

Kelly G, Hallström S (2004) Bearing strength of carbon fibre/epoxy laminates: effects of bolt-hole clearance. Compos Part B Eng 35:331-343. doi:10.1016/j. compositesb.2003.11.001

Khashaba UA, Sebaey TA, Alnefaie KA (2013) Failure and reliability analysis of pinned-joints composite laminates: effects of stacking sequences. Compos Part B Eng 45:1694-1703. doi:10.1016/j.compositesb.2012.09.066

Labanieh AR, Liu Y, Vasiukov D et al (2017) Influence of off-axis in-plane yarns on the mechanical properties of 3D composites. Compos Part A Appl Sci Manuf 98:45-57. doi:10.1016/j.compositesa.2017.03.009

Leong KH, Lee B, Herszberg I, Bannister MK (2000) The effect of binder path on the tensile properties and failure of multilayer woven CFRP composites. Compos Sci Technol 60:149-156. doi:10.1016/S0266-3538(99)00108-6

Li L, Lomov SV, Yan X, Carvelli V (2014) Cluster analysis of acoustic emission signals for 2D and 3D woven glass/epoxy composites. Compos Struct 116:286-299. doi:10.1016/j.compstruct.2014.05.023

Lomov SV, Bogdanovich AE, Ivanov DS et al (2009) A comparative study of tensile properties of non-crimp 3D orthogonal weave and multi-layer plain weave E-glass composites. Part 1: materials, methods and principal results. Compos Part A Appl Sci Manuf 40:1134-1143. doi:10.1016/j.compositesa. 2009.04.032

Lomov SV, Bogdanovich a E, Karahan M et al (2011) Mechanical behaviour of non-crimp 3D woven carbon/epoxy composite under in-plane tensile loading. ICCM 18:1-5

Luo Y, Lv L, Sun B et al (2007) Transverse impact behavior and energy absorption of three-dimensional orthogonal hybrid woven composites. Compos Struct 81:202-209. doi:10.1016/j.compstruct.2006.08.011

Mahadik Y, Hallett SR (2011) Effect of fabric compaction and yarn waviness on 3D woven composite compressive properties. Compos Part A Appl Sci Manuf 42:1592-1600. doi:10.1016/j.compositesa.2011.07.006

Mcclain M, Senior R, Organic TE, Composites M (2012) Overview of recent developments in 3D structures. Albany Eng Compos:1-12

Mittelstedt C, Becker W (2004) Interlaminar stress concentrations in layered structures: part I - a selective literature survey on the free-edge effect since 1967. J Compos Mater 38:1037-1062. doi:10.1177/0021998304040566

Mittelstedt C, Becker W (2007) Free-edge effects in composite laminates. Appl Mech Rev 60:217. doi:10.1115/1.2777169

Mohamed MH, Wetzel KK (2006) 3D woven carbon/glass hybrid spar cap for wind turbine rotor blade. J Sol Energy Eng 128:562-573. doi:10.1115/1. 2349543

Mounien R, Fagiano C, Paulmier P et al (2016) Experimental characterization of the bearing behavior of 3D woven composites. Compos Part B Eng:1-8. doi:10.1016/j.compositesb.2016.10.077
Mouritz AP, Cox BN (2010) A mechanistic interpretation of the comparative in-plane mechanical properties of 3D woven, stitched and pinned composites. Compos Part A Appl Sci Manuf 41:709-728. doi:10.1016/j.compositesa.2010.02.001

Mouritz AP, Bannister MK, Falzon PJ, Leong KH (1999a) Review of applications for advanced threedimensional fibre textile composites. Compos Part A Appl Sci Manuf 30:1445-1461. doi:10.1016/S1359-835X(99)00034-2

Mubeen A (2014) Damage Tolerance of 3D Woven Composites with Weft Binders. The University of Manchester

Muñoz R, Martínez V, Sket F et al (2014) Mechanical behavior and failure micromechanisms of hybrid 3D woven composites in tension. Compos Part A Appl Sci Manuf 59:93-104. doi:10.1016/j.compositesa.2014.01.003

Naik NK, Shembekar PS, Verma MK (1990) On the influence of stacking sequence on notch sensitivity of fabric laminates. J Compos Mater 24:838-852. doi:10. 1177/002199839002400804

Nasution MRE, Watanabe N, Kondo A, Yudhanto A (2014) Thermomechanical properties and stress analysis of 3-D textile composites by asymptotic expansion homogenization method. Compos Part B Eng 60:378-391. doi:10.1016/j.compositesb.2013.12.038

Öndürücü A, Esendemir Ü, Tunay RF (2012) Progressive failure analysis of glassepoxy laminated composite pinned-joints. Mater Des 36:617-625. doi:10. 1016/j.matdes.2011.11.031

Pisano AA, Fuschi P (2011) Mechanically fastened joints in composite laminates: evaluation of load bearing capacity. Compos Part B Eng 42:949-961. doi:10.1016/j.compositesb.2010.12.016

Pochiraju K (1999) Three-dimensionally woven and braided composites. II: an experimental characterization. Polym Compos 20:733-747

Potluri P, Hogg P, Arshad M et al (2012) Influence of fibre architecture on impact damage tolerance in 3D woven composites. Appl Compos Mater 19:799812. doi:10.1007/s10443-012-9256-9

Quinn JP, Mcllhagger AT, Mcllhagger R (2008) Examination of the failure of 3D woven composites. Compos Part A Appl Sci Manuf 39:273-283. doi:10.1016/j. compositesa.2007.10.012

Redman C, Bayraktar H, Mcclain M (2014) Curved beam test Behavior of 3D woven composites.

Rudov-Clark S (2007) Experimental investigation of the tensile properties and failure mechanisms of three-dimensional woven composites.

Saleh MN, Wang Y, Yudhanto A et al (2016a) Investigating the potential of using off-Axis 3D woven composites in composite joints' applications. Appl Compos Mater 24:377-396. doi:10.1007/s10443-016-9529-9

Saleh MN, Yudhanto A, Potluri P et al (2016b) Characterising the loading direction sensitivity of 3D woven composites: effect of z-binder architecture. Compos Part A Appl Sci Manuf 90:577-588. doi:10.1016/j.compositesa.2016.08.028

Seltzer R, González C, Muñoz R et al (2013) X-ray microtomography analysis of the damage micromechanisms in 3D woven composites under low-velocity impact. Compos Part A Appl Sci Manuf 45:49-60. doi:10.1016/j.compositesa. 2012.09.017

Sharp K, Bogdanovich A, Boyle R et al (2013) Wind blade joints based on noncrimp 3D orthogonal woven pi shaped preforms. Compos Part A Appl Sci Manuf 49:9-17. doi:10.1016/j.compositesa.2013.01.012

Shembekar PS, Naik NK (1992) Notched strength of fabric laminates. II: effect of stacking sequence. Compos Sci Technol 44:13-20. doi:10.1016/0266-3538(92)90021-T

Stig F (2012) 3D-woven Reinforcement in Composites. KTH Sweden

Stig F, Hallström S (2009) Assessment of the mechanical properties of a new 3D woven fibre composite material. Compos Sci Technol 69:1686-1692. doi:10.1016/j.compscitech.2008.04.047

Stig F, Hallström S (2013) Influence of crimp on 3D-woven fibre reinforced composites. Compos Struct 95:114-122. doi:10.1016/j.compstruct.2012.07.022

Sun CT, Chu GD (1991) Reducing free edge effect on laminate strength by edge modification. J Compos Mater 25:142-161. doi:10.1016/0010-4361(91)90599-C

Tan P, Tong L, Steven GP, Ishikawa T (2000) Behavior of 3D orthogonal woven CFRP composites. Part I. Experimental investigation. Compos Part A Appl Sci Manuf 31:259-271. doi:10.1016/S1359-835X(99)00070-6

Thoppul SD, Finegan J, Gibson RF (2009) Mechanics of mechanically fastened joints in polymer-matrix composite structures - a review. Compos Sci Technol 69:301-329. doi:10.1016/j.compscitech.2008.09.037

Tong L, Mouritz MB AP (2009b) Chapter 5 3D Woven Composites. In: 3D Fibre Reinforced Polymer Composites

Tong L, Mouritz AP, Bannister M (2009a) Chapter 2 Manufacture of 3D Fibre Preforms. In: 3D Fibre Reinforced Polymer Composites.

Tong L, Mouritz AP, Bannister M (2009b) Chapter 5 3D Woven Composites. In: 3D Fibre Reinforced Polymer Composites. 
Tsai KH, Chiu CH, Wu TH (2000) Fatigue behavior of 3D multi-layer angle interlock woven composite plates. Compos Sci Technol 60:241-248. doi:10.1016/50266-3538(99)00120-7

Turner P, Liu T, Zeng X (2016) Collapse of 3D orthogonal woven carbon fibre composites under inplane tension/compression and out-of-plane bending. Compos Struct 142:286-297. doi:10.1016/j.compstruct.2016.01.100

Umer R, Alhussein H, Zhou J, Cantwell W (2016) The mechanical properties of 3D woven composites. J Compos Mater. doi:10.1177/0021998316681187

Visrolia A, Meo M (2013) Multiscale damage modelling of 3D weave composite by asymptotic homogenisation. Compos Struct 95:105-113. doi:10.1016/j. compstruct.2012.07.018

Walter TR, Subhash G, Sankar BV, Yen CF (2009) Damage modes in 3D glass fiber epoxy woven composites under high rate of impact loading. Compos Part B Eng 40:584-589. doi:10.1016/j.compositesb.2009.04.021

Walter TR, Subhash G, Sankar BV, Yen CF (2010) Monotonic and cyclic short beam shear response of 3D woven composites. Compos Sci Technol 70: 2190-2197. doi:10.1016/j.compscitech.2010.08.022

Wang Y (2006) Effect of fabric structures on the mechanical properties of 3-D textile composites. J Ind Text 35:239-256. doi:10.1177/1528083706057595

Wang M, Cao M, Wang H et al (2017) Drop-weight impact behaviors of 3-D angle interlock woven composites after thermal oxidative aging. Compos Struct 166:239-255. doi:10.1016/j.compstruct.2017.01.046

Warren KC, Lopez-Anido RA, Goering J (2015a) Experimental investigation of three-dimensional woven composites. Compos Part A Appl Sci Manuf 73:242-259. doi:10.1016/j.compositesa.2015.03.011

Warren KC, Lopez-Anido RA, Goering J (2015b) Behavior of three-dimensional woven carbon composites in single-bolt bearing. Compos Struct 127:175-184. doi:10.1016/..compstruct.2015.03.022

Yang G, Sun B, Gu B (2014) Large-scale finite element analysis of a 3D angleinterlock woven composite undergoing low-cyclic three-point bending fatigue. J Text Inst 105:275-293. doi:10.1080/00405000.2013.836785

Yu B, Bradley RS, Soutis C et al (2015a) 2D and 3D imaging of fatigue failure mechanisms of 3D woven composites. Compos Part A Appl Sci Manuf 77:37-49. doi:10.1016/j.compositesa.2015.06.013

Yu B, Bradley RS, Soutis C et al (2016b) A comparison of different approaches for imaging cracks in composites by X-ray microtomography. Philos Trans A Math Phys Eng Sci 374:20160037. doi:10.1098/rsta.2016.0037

Yudhanto A, Iwahori Y, Watanabe N, Hoshi H (2012a) Open hole fatigue characteristics and damage growth of stitched plain weave carbon/epoxy laminates. Int J Fatigue 43:12-22. doi:10.1016/j.jifatigue.2012.02.002

Yudhanto A, Watanabe N, Iwahori Y, Hoshi H (2012b) The effects of stitch orientation on the tensile and open hole tension properties of carbon/epoxy plain weave laminates. Mater Des 35:563-571. doi:10.1016/j.matdes.2011.09.013

\section{Submit your manuscript to a SpringerOpen ${ }^{\circ}$ journal and benefit from:}

- Convenient online submission

- Rigorous peer review

- Open access: articles freely available online

- High visibility within the field

- Retaining the copyright to your article

Submit your next manuscript at $\gg$ springeropen.com 